perinatal deaths. But it is prudent to warn neonatologists that studies which isolate their patients can only be a half truth. Their patients' problems are profoundly influenced by obstetric practice.

Some misconception has arisen over the definition of asphyxia (less commonly but more correctly called hypoxia.) For the purposes of the study the term was applied only to hypoxia arising intrapartum. Liveborn infants who were never able to breathe independently despite resuscitative measures were usually regarded, in the absence of lethal malformation, to be asphyxial deaths. Asphyxia which only developed postnatally but which resulted in death would not have been classified in the asphyxial group. In such circumstances hyaline membrane disease, intraventricular haemorrhage, pneumonia, or malformation were the common aetiological factors. It is important to appreciate that the classification adopted categorises death rather than specifies primary causes of death. Pronouncements on whether death is due to hyaline membrane disease or intraventricular haemorrhage is a very subjective exercise. The incidence of both hyaline membrane disease and intraventricular haemorrhage has risen since 1975 in St Mary's Hospital. The longer survival produced by ventilatory care has necessarily encouraged the resolution of hyaline membranes before death, while intraventricular haemorrhage has had more time to develop. ${ }^{2}$ Most of the suggestions made by $\mathrm{Dr}$ Addy to account for the failure of the deaths from immaturity to decline are reasonable, although the importance of any single factor must be a matter of speculation.

We would take exception, however, to the suggestion that 'Neonatal intensive care, as practised in Manchester, does not save the lives of babies with hyaline membrane disease'. Our study has only shown that there was no significant reduction in deaths secondary to the consequences of being born too soon between 1976 and 1981 . That falls far short of saying that intensive care saved no lives from hyaline membrane disease. It is worth pointing out that a previous study has clearly shown a higher survival in infants admitted from the region to our intensive care unit than those whose transfer proved impossible. ${ }^{3}$

We fully concur, therefore, with Dr Addy's plea that our findings should not be used to belittle neonatal intensive care. It would be tragic if doctors were ever discouraged from innovation in clinical care by a failure of mortality rates to respond immediately to their endeavours. Our study indicates that the problems of being born deficient in surfactant are less easily remedied than those of being born deficient in oxygen. But the fact that intensive care has been so successful in combating the effects of intrapartum hypoxia can only be cause for celebration. That such intensive care is not universally available can only be a cause for sadness.

\footnotetext{
References

${ }^{1}$ Barson AJ, Tasker M, Lieberman BA, Hillier VF. Impact of improved perinatal care on the causes of death. Arch Dis Child 1984;59:199-206.

2 Barson AJ. The changing pattern of perinatal pathology. In: Chiswick ML, ed. Recent advances in perinatal medicine. Edinburgh: Churchill Livingstone, 1983:1-20.
}

${ }^{3}$ Sims DG, Wynn J, Chiswick ML. Outcome for newborn babies declined admission to a regional neonatal intensive care unit. Arch Dis Child 1982;57:334-7.

A J Barson, M Tasker, B A Lieberman, ANd V F Hillier Department of Pathology, St Mary's Hospital, Whitworth Park, Manchester M13 OJH

\section{BPA response to 'healthier children thinking prevention'}

Sir,

As a senior clinical medical officer with administrative duties in the child health service may I comment on the British Paediatric Association's response to this report. Colleagues have expressed similar sentiments on one or both of the following points:

(1) Possibly the general practitioners of the future will undertake a competent and conscientious paediatric surveillance programme for their patients and one sees the logic of this proposal, but to date there is little tangible evidence of this apart from the above 'paper exercise'. Health authorities now have a statutory requirement imposed by the 1981 Education Act to notify education authorities of any child likely to have special education needs by the time he is 2 years old. Gross handicap is obvious, 'hidden handicap' is initially more difficult to detect. One must not let the latter group down in the power/item of service payment game.

(2) Senior clinical medical officers with a paediatric training are convinced that the doctor who obtained a Diploma in Child Health now elevated to a member of the Faculty of Community Medicine (MFCM) (or who has passed the latter examination) has received a training which is largely irrelevant to the present day needs of community paediatrics. Surely the advised higher qualification must be membership of the Royal College of Physicians with a senior registrar background in hospital and community paediatrics; the MFCM could be an optional extra! Unfortunately, one is only too conscious of the serious limitations of the Community Medicine Training Programme and the anachronistic practice in 1984 of someone from this background being responsible for a community paediatric service as is the district medical officer or his specialist in community medicine. The problems caused by this can be very serious, producing a distorted or diminished awareness of service requirements, and very often a lack of commitment to child health which adversely affects the service. In what other 'specialty does a non-clinical, inappropriately qualified 'desk' doctor have responsibility for a clinical service?

Even now it would be eminently more sensible for the suitably qualified and experienced senior clinical medical 
officer with day to day responsibility for the service to have complete autonomy and consequent power to protect/ develop the service, working from the present health authority base. A senior clinical medical officer in child health feels a more natural affinity for the paediatrician with whom he works as a clinical colleague. The BPA must really take the initiative and act swiftly to promote an integrated child health service. Community medicine should be a planning resource only and the faculty bid to stay in control must be firmly resisted.

\section{A Senior Clinical Medical Officer}

\section{Juvenile discitis}

Sir,

Hensey et al ${ }^{1}$ seemed unconvinced of the value of antibiotic treatment in their six cases of juvenile discitis. We have seen and treated four children (three under the age of 5 years) in the past four years with clinical, radiological, and laboratory features consistent with the condition as described by the authors (Table). None of our patients were systemically ill, although one, our first, did present with mild glomerulonephritis and in his case a throat swab yielded beta haemolytic streptococci Lancefield group A. All four patients responded to antibiotic treatment. Penicillin was stopped after 10 days in case 1 with recurrence of backache and inability to walk within a week. His symptoms resolved again within a few days of restarting penicillin and flucloxacillin and he remained well after being given treatment for a further 6 weeks. The other three children received antibiotic treatment for 6 weeks by which time the erythrocyte sedimentation rate had returned to normal in each case.

After two years follow up one of our patients had a recurrence of symptoms, but she again responded to antibiotic treatment with ampicillin and flucloxacillin and has since remained asymptomatic for over two years. We feel that although it is possible that some cases of juvenile discitis may be related to trauma, ${ }^{2}$ infection is the common cause and broad spectrum antibiotic treatment should be offered to all cases. Immobilisation of the spine for a prolonged period has been recommended by some authors ${ }^{3}{ }^{4}$ but we did not find this necessary in any of our patients.

\section{P Shah and C G Miller District General Hospital, Lovely Lane, Warrington WA5 1QG}

Dr Hensey and co-workers comment:

Drs Shah and Miller confirm our opinion that the treatment and origin of juvenile discitis are controversial. ${ }^{1}$ In the patients we described we failed to find any haematological or bacteriological support for an infective

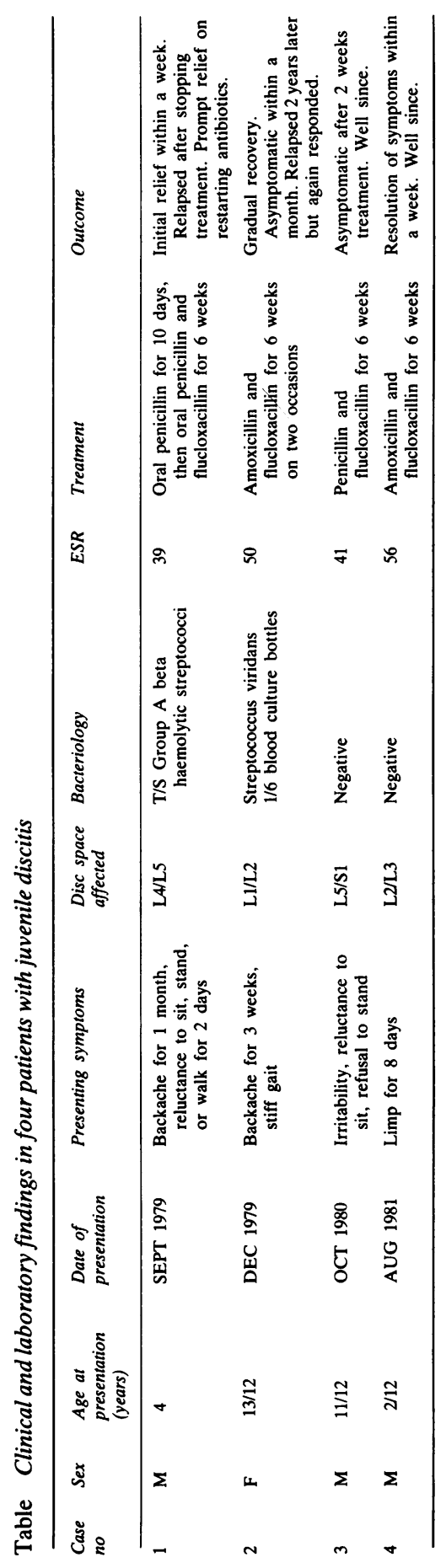

